\title{
Cell Mediated Neural Defense Against Pathogen within Olfactory Neuroepithelium of Fish
}

\author{
SUBRATA DE $^{1}$, SWARAJ SARKAR ${ }^{2}$, SWASTI BARMAN $^{3}$ and Sk SAMIM HOSSIN ${ }^{2}$
}

${ }^{1}$ Mahatma Gandhi University, PurbaMedinipur - 721628, West Bengal, India, Midnapore (West), West Bengal, India, ${ }^{2}$ Vidyasagar University, Midnapore (West) - 721 102, West Bengal, India, Midnapore (West), West Bengal, India, ${ }^{3}$ Department of Zoology, Vidyasagar University, Midnapore (West) - 721 102, West Bengal, India, Midnapore (West), West Bengal, India

Pseudapocryptes lanceolatus (Bloch and Schneider, 1801) and Lepidocephalichthys guntea (Hamilton, 1822) are two different teleostean species showing distinct ecomorphological variation in the olfactory apparatus in respect to their concern environmental habitat [1]. These species are generally residing in turbid or hypoxic condition and have a high risk to sniff variable pathogens along with water during olfaction through the nostrils. The present study pertinently deals with the question that 'How peripheral olfactory neural system protects itself against invading pathogens and restore olfactory neuroepithelial integrity in fish?'

The olfactory apparatus of adult $P$. lanceolatus and L. guntea were dissected out and immediately fixed in $2.5 \%$ glutaraldehyde in $0.1(\mathrm{M})$ phosphate buffer $(\mathrm{pH} .7 .2)$ at $4^{\circ} \mathrm{C}$ for 2 hours (primary fixation) and $1 \%$ osmium tetraoxide in the same buffer for 1 hour (secondary fixation). The ultrathin sections (70-90) $\mathrm{nm}$ were stained with uranyl acetate and lead citrate, examined under transmission electron microscope [TEM: MORGAGNI -268D] operated at 40kV [SAIF, All India Institute of Medical Sciences (AIIMS), New Delhi].

P. lanceolatus and L. guntea are showing common cellular components within the olfactory neuroepithelium (i.e., bipolar sensory receptor cells, supporting cells, basal cells, mucous cells, etc.) enclosing the entire nasal cavity. A large number of variable pathogens are also marked within the nasal cavity adjacent to the mucous lining of olfactory neuroepithelium (Figs. 1A - 1C). Various morphs of rodlet cells, heterophils, macrophages with prominent pseudopodia, plasma cell, mast cell, etc. are distinctly marked at different depths of olfactory neuroepithelium (Figs. 2A - 2D). The holocrine mode of secretory features of rodlet cells are also characterized under TEM. A cellular association of macrophage with phagosomes and plasma cell is also observed within the lower part of the olfactory neuroepithelium (Figs. 2A, 2B and 2C). In lamina propria region, a large number of blood capillaries having variable diameters and developing erythrocytes, endothelial derivatives, etc. are identified which may be an indicative of vasculogenesis (?) in response to hypoxic environmental condition (Figs. 3A and 3C). Apart from that, variable stages of granulocytes, fibroblast cells and mast cells are also found in this region(Figs. 3A-3D).

Environmental hypoxic condition is an important feature which triggers the innate as well as adaptive immune response against invading pathogens [2]. The interaction between macrophage and invading pathogens is not only implicating the role as a scavenger but may also an indicative of the role as antigen presenting cell (APC) to eliminate the pathogen in association with plasma cell (Antibody Producing Cell). Mast cells are also supposed to be involved in innate and adaptive immunity against invading pathogens within the olfactory system [3]. Thus, the frequent vasculogenesis within the lamina propria and functional 
efforts of macrophage, plasma cell, rodlet cell and mast cell are directly involved in maintaining homeostasis against invading pathogens in hypoxic condition.

Acknowledgements:

The authors are thankful to Prof. Ranjan Chakrabarti, The Hon'ble Vice Chancellor, Vidyasagar University, India for his kind support and Prof. T. C. Nag, Department of Anatomy, AIIMS, New Delhi for his academic guidance.
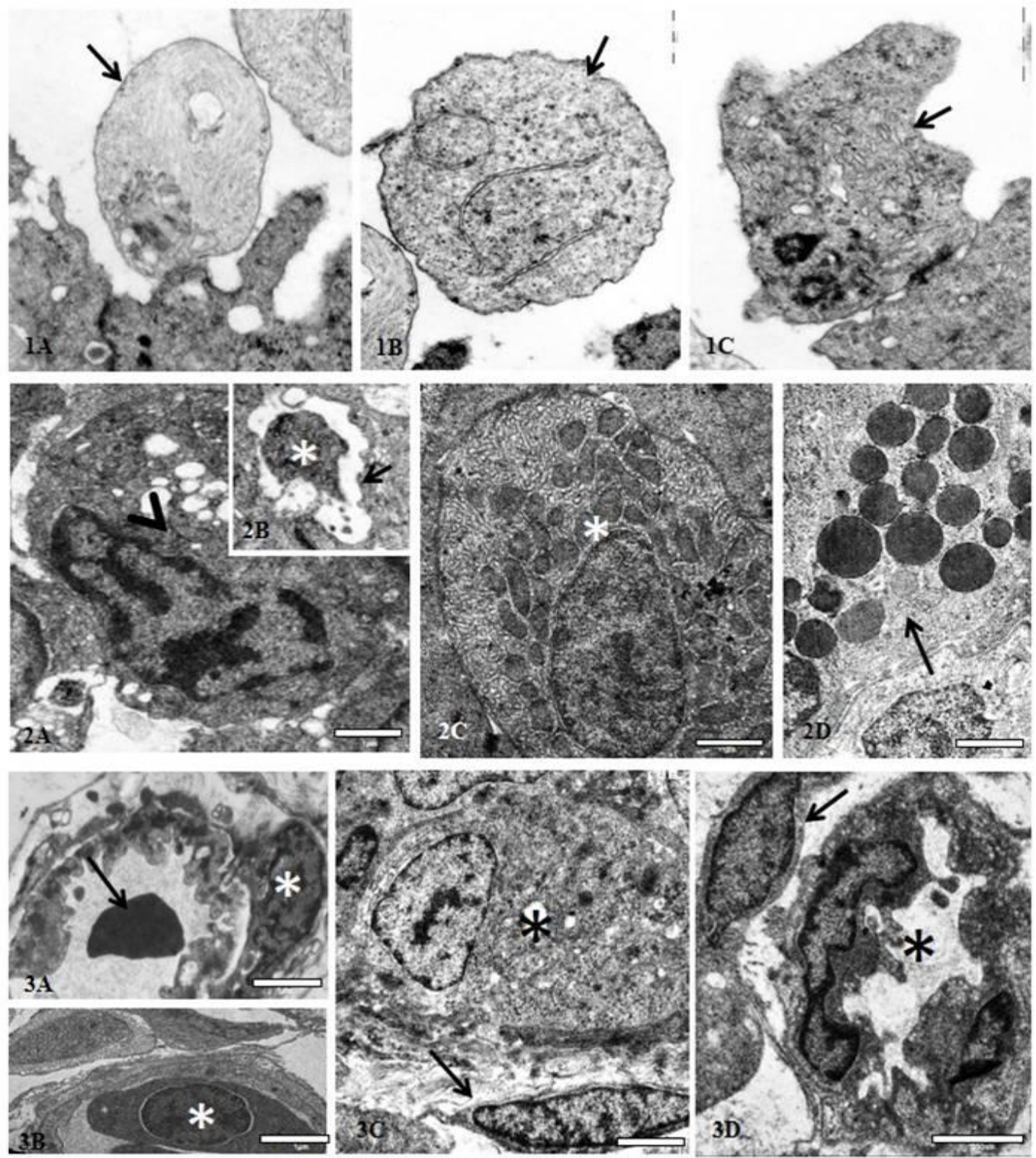

Figure 1. Figures $1[\mathrm{~A}-\mathrm{C}]$ : The electron micrographs show various morphs of invading pathogens (arrows) within the nasal cavity of $P$. lanceolatus. Figures 2 [A-D]: The photomicrographs indicating subcellular features of Macrophage (A), Event of phagocytosis (B), plasma Cell (C) and Mast cell (D) within the olfactory neuroepithelium of P. lanceolatus and L. guntea. A: Macrophage (arrowhead); B: The event of phagocytosis by forming phagosome [pathogen $(*)$, pseudopodia (arrow)]; C: The Plasma cell (*); D: Mast cell (arrow). Figures 3 [A-D]: The subcellular features of lamina propria region of olfactory system in P. lanceolatus and L. guntea. A: The blood capillary with developing erythrocytes (arrow)and endothelial cell (*); B: The blood capillary showing nucleated mature erythrocyte (*). C: The Granulocyte 
(*) and fibroblast cell (arrow); C: Developing stage of blood capillary with immature blood cells (*) associated with fibroblast cell (arrow).

\section{References}

[1]Sarkar S.K., Acharya A., Jana S., De S.K., Folia Morphol. 73(2): (2014), p. 122-128.

[2] Eilíse M Ryan, Moira KB Whyte, Sarah R Walmsley, Current Opinion in Physiology, 7 (2019), p. 1520.

[3] De S. K., Sarkar S.K., Jana S, Barman S., Hossin, S., Chem. Senses, 45 (2020): p. 149. 